\title{
Scalp cooling to prevent chemotherapy-induced hair loss: practical and clinical considerations
}

\author{
Floortje Mols • Corina J. van den Hurk • \\ Ad J. J. M. Vingerhoets • Wim P. M. Breed
}

Received: 29 February 2008 / Accepted: 22 May 2008 / Published online: 17 June 2008

(C) The Author(s) 2008

\begin{abstract}
Objective The objective of this prospective multicenter study was to obtain insight into the severity and burden of hair loss among cancer patients treated with chemotherapy. In addition, we described the effectiveness and burden of scalp cooling and the satisfaction with wigs, with hair regrowth, and with body image.

Materials and methods Breast cancer patients treated with $(n=98)$ and without $(n=168)$ scalp cooling completed questionnaires before chemotherapy and 3 weeks and 6 months after completion of chemotherapy.

Results Scalp cooling was effective in preventing chemotherapy-induced hair loss in 32 of 62 available patients (52\%). Even though patients knew hair loss was temporary,
\end{abstract}

Mols and Hurk contributed equally to this work.

\section{F. Mols}

CoRPS - Center of Research on Psychology in Somatic Diseases,

Tilburg University,

Tilburg, the Netherlands

F. Mols $\cdot$ C. van den Hurk $\cdot$ W. Breed

Comprehensive Cancer Center South (CCCS),

Eindhoven Cancer Registry,

Eindhoven, the Netherlands

C. van den Hurk

Department of Clinical Oncology,

Leiden University Medical Center,

Leiden, the Netherlands

A. Vingerhoets

Clinical Psychology Section, Tilburg University,

Tilburg, the Netherlands

F. Mols $(\varangle)$

CoRPS, Department of Medical Psychology, Tilburg University,

Tilburg, the Netherlands

e-mail: F.Mols@uvt.nl it was a burden to $54 \%$ of them $(n=100)$. Scalp cooling was a burden for only 17 out of 51 patients (33\%). Most patients who used a wig or head cover were satisfied with it $(82 \%, n=126)$. Patients were moderately satisfied with the regrowth of their hair after chemotherapy (mean 11.6; SD 2.53; range $0-20$ ). Successfully cooled patients rated their hair as less important for their body image compared to patients who did experience hair loss $(p=0.014)$.

Discussion Chemotherapy-induced hair loss is perceived as burdensome. It may be prevented by offering scalp cooling which is often an effective method to prevent this form of hair loss and is tolerated well by patients. However, if possible, scalp-cooling techniques should be improved and their effectiveness should be increased because if scalp cooling is unsuccessful, patients' rate their hair loss as more burdensome compared to noncooled patients.

Keywords Breast cancer - Scalp cooling · Hair loss . Alopecia $\cdot$ Chemotherapy $\cdot$ Wig $\cdot$ Body image

\section{Introduction}

To date, the majority of breast cancer patients are treated with surgery, often in combination with radiotherapy. These therapies are often combined with chemotherapy (Dutch guidelines; http://www.oncoline.nl), which may cause severe side effects [19]. Patients rate hair loss as among the most severe side effects of chemotherapy $[4,7,9,12,22-24,27$, 37]. Since the 1970s, preventive efforts such as tourniquet, medication, and scalp cooling have been applied to prevent chemotherapy-induced hair loss [10]. Currently, scalp cooling is the most commonly used method.

Seven randomized clinical studies have been published which examined the effectiveness of scalp cooling $[13,16$, 
$21,25,30,34,36]$. These studies randomized a total of 233 patients. In six of these studies, scalp cooling was considered to be effective. The average reported success rate of scalp cooling in studies carried out before 1995, with a total number of 1,563 patients, was $56 \%$ and from 1995 onwards the success rate was $73 \%$ with a total of 1,047 patients included [17]. Despite this relatively high success rate, scalp cooling offered is very limited; e.g., in February 2008, only $36 \%$ of all Dutch hospitals offered scalp cooling and, moreover, only to a selected number of patients. Reasons for this are, among others, the underestimation of the impact of hair loss and overestimation of the burden of scalp cooling on a patient by the oncologists and nurses and the lack of knowledge on the current effectiveness of scalp cooling.

The present study is the first more systematic study that specifically addresses quality of life and scalp-cooling satisfaction in a multicenter context and has three main objectives. The first objective was to obtain insight into the severity and burden of hair loss among cancer patients treated with chemotherapy. The second objective was to describe the effectiveness and burden of scalp cooling. The third objective was to describe the satisfaction with a wig and with hair regrowth in patients who lost their hair after chemotherapy (because they did not receive scalp cooling or because scalp cooling failed). The final objective of this study was to measure the difference in body image between patients who were or were not treated with scalp cooling.

\section{Materials and methods}

\section{Setting and participants}

Breast cancer patients were enrolled in this prospective multicenter study between October 2004 and February 2007. Thirteen hospital locations participated in this study, with six offering scalp cooling. If patients in the scalpcooling hospitals did not chose for scalp cooling, they were not included in this study.

Specialized oncology nurses informed patients about the study. Patients who decided to participate received a set of questionnaires before the start of chemotherapy, 3 weeks after the last cycle of chemotherapy and 6 months after chemotherapy. If a questionnaire was not returned, the patient received a reminder. Approval for this study was obtained from the Medical Ethics Committees of all participating hospitals. All study participants provided written informed consent.

Inclusion and exclusion criteria

Inclusion criteria were treatment for breast cancer with one of the following intravenous chemotherapies: four or six adriamycine $\left(60 \mathrm{mg} / \mathrm{m}^{2}\right)$ and cyclophosphamide $\left(600 \mathrm{mg} / \mathrm{m}^{2}\right)$ treatments; five or six 5 -fluorouracil $\left(500 \mathrm{mg} / \mathrm{m}^{2}\right)$, epirubicine $\left(90 \mathrm{mg} / \mathrm{m}^{2}\right)$, and cyclophosphamide $\left(500 \mathrm{mg} / \mathrm{m}^{2}\right)$ treatments; five or six 5 -fluorouracil $\left(500 \mathrm{mg} / \mathrm{m}^{2}\right)$, adriamycine $\left(50 \mathrm{mg} / \mathrm{m}^{2}\right)$, and cyclophosphamide $\left(500 \mathrm{mg} / \mathrm{m}^{2}\right)$ treatments; and five or six docetaxel $\left(75 \mathrm{mg} / \mathrm{m}^{2}\right)$, adriamycine $\left(50 \mathrm{mg} / \mathrm{m}^{2}\right)$, and cyclophosphamide $\left(500 \mathrm{mg} / \mathrm{m}^{2}\right)$ treatments. These chemotherapies had to be given in the adjuvant setting in a 21-day cycle. Patients treated with intravenous trastuzumab for a year following chemotherapy were excluded because of the possible influence of long-lasting intensive contact with oncology nurses and other cancer patients on the measures. Patients were excluded if they lacked basic proficiency in Dutch, if they were unable to understand the patient information folder, or if they suffered from alopecia before the onset of chemotherapy.

\section{Measures}

\section{Patient and tumor characteristics}

The measured patient and tumor characteristics were date of birth, marital status, educational level, type of surgery, and lymph node dissection.

\section{Severity of hair loss}

The severity and importance of hair loss was measured by asking patients if they felt the need to wear a wig or other head covering. We defined the success of cooling on the basis of whether the patient reported the use of a wig or head covering. Furthermore, the severity of hair loss was reported by patients on the four-point scale for alopecia of the World Health Organization (WHO) with grade 0 for no hair loss, grade 1 for mild hair loss, grade 2 for pronounced hair loss, and grade 3 for total hair loss [40]. In addition, a visual analog scale (VAS) was applied ranging from 0 for no hair loss to 100 for total baldness. The severity of hair loss was measured 3 weeks after the last cycle of chemotherapy.

\section{Burden of hair loss}

A newly developed questionnaire assessed the impact of hair loss. Part of the items were selected from questionnaires with respect to alopecia androgenetica $[6,11,15]$; other items were self-defined based on discussions with female cancer patients. This measure consisted of 40 statements that could be rated on a four-point Likert scale ranging from "not at all" to "very much." Higher scores indicated higher burden of hair loss. The answers on the four-point Likert scale were divided into two groups, 
namely, patients who did or did not agree with a particular statement. Patients who did not receive scalp cooling as well as scalp-cooled patients who reported hair loss (defined as WHO score grades 1, 2, or 3) completed the questionnaire 3 weeks and 6 months following chemotherapy.

\section{Burden of scalp cooling}

The burden of scalp cooling was evaluated by nine selfdefined items which were based on complaints reported by patients who were treated with scalp cooling in the past. The items concerned the psychological burden, physical effects, and the influence of uncertainty about the final result of cooling. Response format was a six-point Likert scale ranging from "not at all" to "a lot." Higher scores thus indicate a higher burden of scalp cooling. The answers on the six-point Likert scale were divided into two groups, namely, patients who did or did not agree with a particular statement. Furthermore, patients were asked whether or not they had taken pain killers during scalp cooling.

This questionnaire was completed by 51 out of 98 scalpcooled patients. This was due to the fact that this questionnaire was added to our set of questionnaires at a later stage and only in some of the hospitals which offered scalp cooling. Since patients were asked to fill out this questionnaire after each cooling, we received a total of 153 completed questionnaires.

\section{Wig use}

Patients were asked what kind of head covering they used and if they wore the head covering inside the house, only outside the house, or both.

A newly developed questionnaire additionally evaluated the satisfaction with wigs and head coverings and was based on consultations with an expert panel (nurses and patients). This measure consisted of 18 statements rated on a four-point Likert scale ranging from "not at all" to "very much." Higher scores indicated higher levels of satisfaction with wigs or head coverings. Patients completed the questionnaire 3 weeks and 6 months following chemotherapy.

\section{Hair regrowth}

Satisfaction with hair regrowth was measured by a fiveitem questionnaire addressing the rapidity of regrowth, length and thickness, color, and hair style (curly or straight). The answer categories were rated on a four-point Likert scale ranging from "not at all" to "very much." Higher scores indicated higher levels of satisfaction with hair regrowth. The answers on the four-point Likert scale were divided into two groups, namely, patients who were or were not satisfied with hair regrowth. The questionnaire was filled out 6 months after completing chemotherapy by patients who reported a score between 1 and 3 on the WHO scale for hair loss.

\section{Body image}

Body image was assessed with the revised version of the body image scale (BIS), consisting of ten items rated on a four-point Likert scale ranging from "not at all" to "very much." The sum score of the ten items ranged from 0 to 30 with higher scores representing increased symptoms or distress with regard to body image. The BIS has high reliability (Cronbach's alpha 0.93) and validity [18].

Concern over body image was assessed by the Measure of Body Apperception (MBA) questionnaire [5]. Scores were calculated for two subscales, namely, "concern about physical appearance" and "concern about body integrity." These subscales both consisted of four items and measured personal investment in both aspects of body image, rather than assessing the body image the person currently holds [5]. Two self-defined items were added to the MBA to measure the importance of hair for a person's body image. Response options of the subscales and self-defined items ranged from "strongly agree" to "strongly disagree." The scores were rated on a scale from 1 to 5 , with higher scores meaning more concerns or higher importance. This questionnaire was completed before chemotherapy and 3 weeks after the completion of chemotherapy.

\section{Statistical analyses}

Statistical analyses were performed using SAS (version 9.1 for Windows, SAS institute Inc., Cary, NC, USA). Patient and tumor characteristics were compared between scalpcooled patients and not scalp-cooled patients by chi-square tests for categorical variables.

From the questionnaire on the burden of hair loss, ten statements were selected that caused the most burden to patients. We reported the number and percentage of questionnaires on which the statements were answered affirmatively. The same procedure was followed for all statements on the questionnaires: "burden of scalp cooling," "hair regrowth," and "wig use."

One week prior to chemotherapy, body image was compared between those who were going to be treated with scalp cooling and those who were not. Three weeks after chemotherapy, body image was compared between patients that were successfully cooled, not successfully cooled, and patients that did not receive scalp cooling. All group comparisons were made with analyses of variance followed by Tukey's test for multiple group comparison. 
Fig. 1 Flow chart of the data collection process

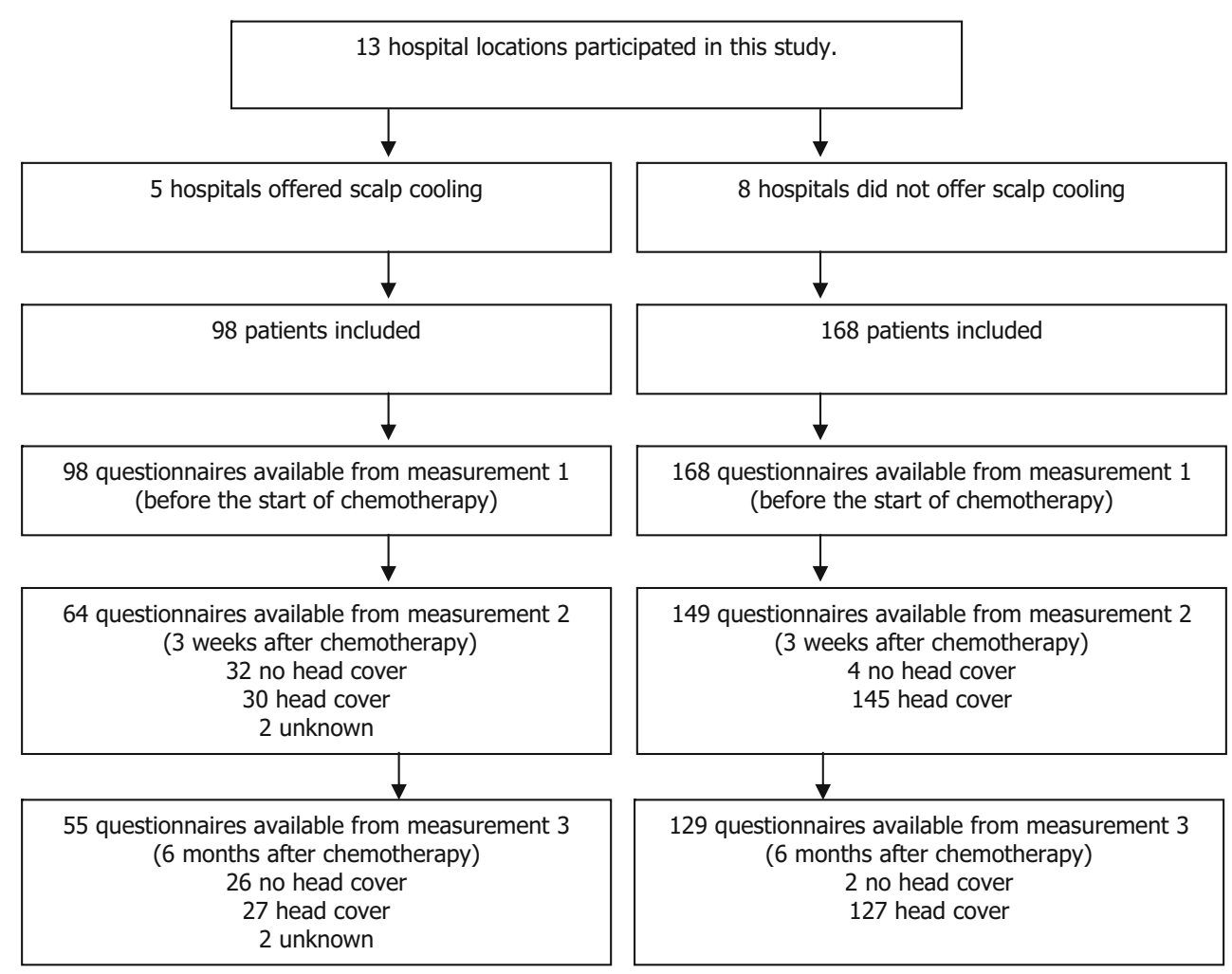

Legend: Dropout during the study occurred due to a variety of reasons. Most often mentioned were logistical problems.

\section{Results}

Patient and tumor characteristics

Ninety-eight patients received scalp cooling and 168 control patients were included who were treated in hospitals where no scalp cooling was available. The participants received the questionnaires at three points in time. The numbers of participants, according to measurement moment, are presented in Fig. 1. In total, 184 (68\%) participants responded. Dropout during the study occurred due to a variety of reasons. Most often mentioned were logistical problems.

Patient and tumor characteristics of breast cancer patients treated with or without scalp cooling are presented in Table 1 . These characteristics did not differ significantly between both patient groups.

\section{Severity of hair loss}

Three weeks after chemotherapy, data were available of $65 \%$ of cooled patients $(n=64)$ and $89 \%$ of not cooled patients $(n=149)$. Scalp cooling was effective in preventing chemotherapy-induced hair loss in 32 of 62 evaluable patients. Data on two patients were missing; therefore, they were excluded from further analyses (Fig. 1). In patients who did not receive scalp cooling $(n=149)$, all but four needed a wig or head cover. These four patients were however completely bald. Because of the low number, these four patients were excluded from further analyses.

Table 1 Sociodemographic and clinical characteristics of breast cancer patients treated with or without scalp cooling before the start of chemotherapy

\begin{tabular}{llll}
\hline & $\begin{array}{l}\text { Scalp } \\
\text { cooling, } \\
n=98, n(\%)\end{array}$ & $\begin{array}{l}\text { No scalp } \\
\text { cooling, } \\
n=168, n(\%)\end{array}$ & $p$ value \\
& 49.8 & 49.7 & \\
\hline $\begin{array}{l}\text { Mean age at time of survey } \\
\text { Surgery }\end{array}$ & $43(44)$ & $94(56)$ & 0.1609 \\
$\quad \begin{array}{l}\text { Total mastectomy } \\
\text { Breast conserving surgery }\end{array}$ & $50(51)$ & $68(40)$ & \\
Lymph node dissection & & & \\
Yes & $79(81)$ & $129(77)$ & 0.4238 \\
No & $15(15)$ & $35(21)$ & \\
Marital status & $76(78)$ & $124(74)$ & 0.3060 \\
Married & $11(11)$ & $29(17)$ & \\
Not married or divorced & $11(11)$ & $13(8)$ & \\
Living together & & & \\
Education level & $42(43)$ & $91(55)$ & 0.1619 \\
Low & $31(32)$ & $42(26)$ & \\
Medium & $24(25)$ & $31(19)$ & \\
High & $1(1)$ & $4(2)$ & \\
Missing & & & \\
\hline
\end{tabular}


The mean rating of hair loss on the VAS scale among successfully cooled patients was 49 (range 17 to 97) while not successfully cooled patients rated a mean of 79 (range 30 to 100). Patients who did not receive scalp cooling reported most hair loss, namely, a mean of 85 (range 9 to 100). These differences in self-reported hair loss were statistically significant $(p<0.001)$.

Extent of hair loss was also rated by patients on the WHO scale. The mean WHO score among successfully cooled patients 3 weeks after chemotherapy was 1.4 (range 0 to 3 ) while not successfully cooled patients rated a mean of 2.6 (range 0 to 3). Patients who did not receive scalp cooling reported the most hair loss, namely, a mean of 2.9 (range 0 to 3 ).

\section{Burden of hair loss}

Out of a list of 40 statements about the burden of hair loss to a patient, the ten statements that were most frequently confirmed 3 weeks and 6 months following chemotherapy were reported in Table 2. On $71 \%$ of questionnaires, it was stated that hair loss made patients feel unattractive and $58 \%$ of questionnaires stated that hair loss was a problem for patients. Furthermore, $54 \%$ of questionnaires showed that, even though patients knew hair loss was temporary, it was a burden to them.

\section{Burden of scalp cooling}

Only 51 of 98 scalp-cooled patients completed the questionnaire about the burden of scalp cooling. These were the

Table 2 Ten statements that caused the most burden of hair loss 3 weeks and 6 months after chemotherapy

\begin{tabular}{ll}
\hline Statements $^{\mathrm{a}}$ & $n(\%)^{\mathrm{b}}$ \\
\hline $\begin{array}{l}\text { I do not feel attractive because of my hair loss } \\
\text { Hair loss was a problem for me }\end{array}$ & $130(71)$ \\
$\begin{array}{l}\text { Even though my hair loss was temporary, I found it a } \\
\text { burden }\end{array}$ & $100(54)$ \\
$\begin{array}{l}\text { I was not satisfied with myself because of my hair loss } \\
\text { I was very aware of myself because of my hair loss }\end{array}$ & $92(50)$ \\
$\begin{array}{l}\text { In the past few weeks-months, I checked my hair loss in the } \\
\text { mirror regularly }\end{array}$ & $86(47)$ \\
$\begin{array}{l}\text { I talked to my friends about my hair loss } \\
\text { The hair loss of my eyes (eyelashes) was a burden to me }\end{array}$ & $82(45)$ \\
The hair loss of my eyebrows was a burden to me & $69(36)$ \\
I was looking for some elucidation about my looks because & $61(33)$ \\
of my hair loss &
\end{tabular}

$n$ Number of questionnaires filled out by patients who did not receive scalp cooling as well as scalp-cooled patients who reported hair loss, 3 weeks and 6 months following chemotherapy

${ }^{a}$ Out of a list of 40 statements, ten statements about hair loss that caused the most burden to patients are reported in this table.

${ }^{\mathrm{b}}$ The number and percentage of patients that answered the statements confirmatively on one or more occasions.
Table 3 The burden of scalp cooling

\begin{tabular}{lcc}
\hline Statements $^{\mathrm{a}}$ & $\begin{array}{l}\text { Number of } \\
\text { questionnaires } \\
(\%)^{\mathrm{b}}\end{array}$ & $\begin{array}{c}\text { Number of } \\
\text { patients (\%) }\end{array}$ \\
\hline Scalp cooling was a burden to me & $25(16)$ & $17(33)$ \\
The cooling was cold & $43(28)$ & $20(39)$ \\
The cooling gave me a headache & $21(14)$ & $12(24)$ \\
The 'cold cap' was heavy & $21(14)$ & $15(29)$ \\
I was able to tolerate the cooling of & $53(35)$ & $27(53)$ \\
my scalp & $14(9)$ & $10(20)$ \\
I got dizzy during the cooling & $20(13)$ & $14(27)$ \\
I felt bored during the cooling & $48(31)$ & $22(43)$ \\
I worry a lot lately about the & & \\
possibility of failure of scalp & & \\
cooling & & \\
Lately, I thought a lot about the & $74(48)$ & \\
result of scalp cooling & &
\end{tabular}

${ }^{\text {a }}$ Statements are listed in this table in the same order of appearance as in the questionnaire.

${ }^{\mathrm{b}}$ The number and percentage of questionnaires on which the statements were answered affirmatively.

${ }^{\mathrm{c}}$ The number and percentage of patients that answered the statements confirmatively on one or more occasions.

patients who underwent a maximum of six cycles of scalp cooling and were thus asked to complete a maximum of six questionnaires. Fifty-one patients filled out the questionnaire during the first cycle; 46 patients also filled out the second questionnaire; 31 patients also did questionnaire three; 16 patients did questionnaire four; nine patients finished the fifth questionnaire and no one finished the last one. Therefore, data of 153 questionnaires were obtained.

In Table 3, we listed the statements of the questionnaire on the burden of scalp cooling and the percentage of questionnaires on which the statements were answered confirmatively. Furthermore, we added data on the number and percentage of patients who answered the statements confirmatively on one or more occasions. On 25 questionnaires $(16 \%)$, it was indicated that scalp cooling was a burden; this was filled out by 17 patients on one or more occasions. The statement; "I was able to tolerate the cooling of my scalp" was answered affirmatively on 53 questionnaires $(35 \%)$ by 27 patients. Twenty-one questionnaires $(14 \%)$ indicated that scalp cooling gave patients $(n=12)$ a headache. However, only nine patients occasionally took a pain killer to relieve a headache (data not shown). On 74 questionnaires (48\%), it was indicated that patients thought frequently about the result of scalp cooling; this was filled out by 31 patients on one or more occasions.

\section{Wig use}

All patients with severe hair loss induced by chemotherapy $(n=175 ; 30$ not successfully cooled and 145 not cooled) 
reported the use of a wig and/or other head cover. Most patients used more than one head cover; a wig was used by $81 \%$ of patients, $51 \%$ used a scarf, $23 \%$ used a cap, and $8 \%$ wore a hat. Seventy-six percent of patients who used a wig or head cover made use of it both inside and outside the house. Furthermore, 37\% reported to wear a wig or head cover merely outdoors and only one patient wore it just indoors.

In Table 4, we listed all 18 statements of the questionnaire on wig use and the percentage of questionnaires that were answered affirmatively 3 weeks and 6 months after chemotherapy. On 126 questionnaires (82\%), it was stated that patients were satisfied with their wig; it looked a lot like their own hair $(n=103 ; 67 \%)$; it fitted nicely round their scalp $(n=119 ; 77 \%)$ and on only a minority of questionnaires $(n=10 ; 1 \%)$ patients complained about irritation to the skin. However, in 91 questionnaires (59\%), patients

Table 4 The burden of wearing a wig or head cover 3 weeks and 6 months after chemotherapy

\begin{tabular}{|c|c|}
\hline Statements ${ }^{\mathrm{a}}$ & $n(\%)^{\mathrm{b}}$ \\
\hline My wig fitted nicely round my scalp & $119(77)$ \\
\hline I was constantly aware of wearing a wig or head cover & $96(62)$ \\
\hline $\begin{array}{l}\text { Wearing a head cover made me feel watched by other } \\
\text { people }\end{array}$ & $35(23)$ \\
\hline My wig caused irritation to the skin & $10(1)$ \\
\hline I was satisfied with my wig or head cover & $126(82)$ \\
\hline My wig looked a lot like my own hair & $103(67)$ \\
\hline $\begin{array}{l}\text { When wearing a wig, I felt just as attractive as before my } \\
\text { hair fell out }\end{array}$ & $73(47)$ \\
\hline By wearing a wig, I felt confident about myself & $81(53)$ \\
\hline $\begin{array}{l}\text { It bothered me that, on some occasions, wearing a wig } \\
\text { caused sweating }\end{array}$ & $56(36)$ \\
\hline $\begin{array}{l}\text { I felt ashamed of myself when I was not wearing my wig or } \\
\text { head cover }\end{array}$ & $53(34)$ \\
\hline $\begin{array}{l}\text { My partner preferred to see me with my wig or head cover } \\
\text { instead of without }\end{array}$ & $29(19)$ \\
\hline $\begin{array}{l}\text { Wearing a wig made my head feel warm and that } \\
\text { bothered me }\end{array}$ & $51(33)$ \\
\hline With activities like exercising, my wig was an obstruction & $54(35)$ \\
\hline $\begin{array}{l}\text { I was worried about the possibility of my wig moving or } \\
\text { falling off }\end{array}$ & $39(25)$ \\
\hline $\begin{array}{l}\text { My kids preferred to see me with my wig or head cover } \\
\text { instead of without }\end{array}$ & $50(32)$ \\
\hline My wig was expensive & $91(59)$ \\
\hline $\begin{array}{l}\text { When wearing a wig, I felt more feminine compared to not } \\
\text { wearing a wig }\end{array}$ & $85(55)$ \\
\hline My wig was easily distinguishable from my own hair & $12(1)$ \\
\hline \multicolumn{2}{|c|}{$\begin{array}{l}\text { a Statements are listed in this table in the same order of appearance as } \\
\text { in the questionnaire. In this table, data were included from } 3 \text { weeks } \\
\text { and } 6 \text { months after chemotherapy for patients wearing a wig or head } \\
\text { cover. } \\
\text { b The number and percentage of questionnaires on which the state- } \\
\text { ments were answered affirmatively. }\end{array}$} \\
\hline
\end{tabular}

stated that they felt that their wig was expensive and that they were constantly aware of wearing it $(n=96 ; 62 \%)$.

Hair regrowth

Six months after chemotherapy, patients who had suffered from hair loss $(n=172)$ were moderately satisfied with hair regrowth (mean 11.6; SD 2.53; range 0-20). Satisfaction with hair regrowth did not differ significantly between patients who underwent scalp cooling and the control group.

Most patients indicated that they were satisfied with the thickness of their hair $(86 \%, n=147)$ and with the speed at which their hair grows $(75 \%, n=129)$. In addition, most patients were satisfied with the texture of their hair (curly or straight; $73 \%, n=125)$, the current length of their hair $(72 \%, n=121)$, and the color of their hair $(57 \%, n=98)$.

\section{Body image}

Before the initiation of chemotherapy, participants in the hospitals that offered scalp cooling reported somewhat more concern about appearance (mean 3.27 vs. $3.02 ; p=0.03$ ) compared to patients in the hospitals that did not offer scalp cooling (Table 5). Three weeks after chemotherapy, scalpcooled patients who did not need a wig reported that their hair had a significant $(p=0.01)$ lower importance for their body image (mean 4.09; SD 0.86) compared to unsuccessfully scalp-cooled patients who needed a wig (mean 4.50; SD 0.63 ) and patients not treated with scalp cooling (mean 4.27; SD 0.81).

\section{Discussion}

The aim of the present study was to obtain insight into the impact that scalp cooling to prevent hair loss during chemotherapy has on the patient. Furthermore, the objective was to evaluate the burden of hair loss and the satisfaction with wigs and with hair regrowth in patients who did lose their hair. Finally, we compared body image between patients who did and did not experience hair loss.

\section{The effectiveness of scalp cooling}

Approximately $50 \%$ of patients that received scalp cooling did not need a wig and were therefore considered successfully cooled. This percentage seems somewhat low because the average success rate of scalp cooling in studies published after 1995 was 73\% [17]. In the literature, wide variations of success rates of scalp cooling have been reported. The success depends upon many factors like type of applied cytostatics, doses, number of chemotherapy courses, admission methods, and scalp-cooling method [1, 
Table 5 Body image 1 week prior to chemotherapy and 3 weeks after chemotherapy among patients treated with and without scalp cooling

\begin{tabular}{|c|c|c|c|c|c|c|c|}
\hline & \multicolumn{3}{|c|}{1 week prior to chemotherapy } & \multicolumn{4}{|c|}{3 weeks after chemotherapy } \\
\hline & $\begin{array}{l}\text { Scalp } \\
\text { cooling } \\
\text { Mean (SD) }\end{array}$ & $\begin{array}{l}\text { No scalp } \\
\text { cooling } \\
\text { Mean (SD) }\end{array}$ & $p$ value & $\begin{array}{l}\text { Scalp cooled, } \\
\text { no head cover } \\
\text { Mean (SD) }\end{array}$ & $\begin{array}{l}\text { Scalp cooled, } \\
\text { head cover } \\
\text { Mean (SD) }\end{array}$ & $\begin{array}{l}\text { No cooling, } \\
\text { head cover } \\
\text { Mean (SD) }\end{array}$ & $p$ value \\
\hline \multicolumn{8}{|l|}{ Body image (BIS; range $0-30$ ) } \\
\hline Total score & $7.71(4.97)$ & $7.24(5.76)$ & 0.5130 & $9.13(6.00)$ & $12.18(5.94)$ & $9.74(5.93)$ & 0.0984 \\
\hline \multicolumn{8}{|c|}{ Concern about body image (MBA; range $1-5$ ) } \\
\hline Concern about appearance & $3.27(0.76)$ & $3.02(0.89)$ & 0.0274 & $2.97(0.88)$ & $3.23(0.91)$ & $3.08(0.87)$ & 0.2005 \\
\hline Concern about body integrity & $2.59(0.89)$ & $2.49(1.02)$ & 0.4393 & $2.59(1.00)$ & $3.02(0.99)$ & $2.66(0.96)$ & 0.9060 \\
\hline \multicolumn{8}{|l|}{ Importance of hair for body image } \\
\hline My hair is important to me & $4.43(0.83)$ & $4.25(0.83)$ & 0.0551 & $4.09(0.86)$ & $4.50(0.63)$ & $4.27(0.81)$ & 0.0141 \\
\hline My hair is important for my appearance & $4.25(0.68)$ & $4.09(0.93)$ & 0.1494 & $3.94(0.84)$ & $4.40(0.62)$ & $4.14(0.86)$ & 0.0719 \\
\hline
\end{tabular}

$8,36]$. The recent, more intensive, adjuvant chemotherapy treatments in breast cancer may explain the relatively low success percentage of about $50 \%$ in this study. Furthermore, the definition of successfully cooled differs considerably among studies. Wearing a wig or head cover may be considered the most important criterion to determine if patients consider their scalp cooling as successful. However, graded scales, like the WHO scale, are also used [17]. In this study, we used both methods. In addition, our relatively low success rate of scalp cooling was defined 3 weeks after the completion of chemotherapy. However, it is possible that success of scalp cooling in other studies is measured earlier (e.g., cycle 3) and not always at the end of all cycles. This could also cause a difference in success rates between other studies and our study. Another possible explanation for our rather low success rate is the fact that the present study is a multicenter study which generally is associated with lower success rates in all kinds of evaluation studies compared to studies performed in a single center. Also, publication bias might be a factor; it is possible that studies having achieved low success rates have not been published after 1995 .

\section{The burden of hair loss}

Hair loss was rated as being a source of distress to patients and this finding confirms results reported in the literature on this topic. A number of studies have shown that a considerable number of cancer patients experience alopecia as distressing [23, 31, 39]. Furthermore, alopecia is ranked among the three most troublesome side effects of chemotherapy, together with vomiting and nausea $[4,7,37]$.

\section{The burden of scalp cooling}

This study showed that patients did not perceive scalp cooling as being burdensome. We found low rates of complaints which is in accordance with literature about the acceptability and tolerance of scalp cooling [17, 20, 26, 32-
34]. Twelve patients indicated that scalp cooling gave them a headache; however, only nine patients occasionally took a pain killer to relieve a headache.

The satisfaction with wigs

All respondents coped with hair loss with a strategy involving camouflaging and hiding; they wore wigs or other head covers in an attempt to hide their hair loss. Alopecia is in particular hided outside the house, when being exposed to others with whom the patient does not wish to share the visible stigma. On the other hand, corroborating previous research [35], an important minority of patients do not hide alopecia inside their own homes when being with their partner, family, and friends who know about the hair loss. Wearing a wig "repairs" your physical appearance, restores corporal integrity, and prevents the patients and others of being constantly reminded of cancer. Patients in our study reported that their wigs were not easily distinguishable from their own hair which supports the idea that wigs were mostly worn to look normal, in any case not looking sick, for themselves and others [39].

The satisfaction with hair regrowth

Hair loss from chemotherapy is temporary; however, how it will grow back is unpredictable; sometimes, the new hair has a different color or texture $[2,14,39]$. Six months after having completed chemotherapy, patients were generally satisfied with their hair regrowth. Since nobody had experienced previous chemotherapy, they did not know what they could expect concerning the regrowth of hair. Patients who experienced severe hair loss or complete baldness have several centimeters of hair within half a year. In patients with bald spots or thinned hair (because scalp cooling was not totally preventive for hair loss and who did not shave their hair), some hair regrowth directly causes a 
thicker head of hair and camouflaging is not needed anymore. Patients in this study were very satisfied with the texture of their hair but were less satisfied with its color.

\section{Body image}

Body image did not differ between patients who did and did not lose their hair 3 weeks after chemotherapy. These findings confirm the results of a prior study among 77 cancer patients receiving chemotherapy, which also demonstrated that patients with alopecia had comparable scores on body image compared to those without alopecia. The negative effect of hair loss on body image may have been minimized by the process of adaptation to hair loss [38] and possibly by the positive effects of the wig. However, a study on changes in body image during chemotherapy among 136 women with gynecologic malignancies who experienced alopecia showed that chemotherapy-induced alopecia had an adverse effect on body image [29]. In addition, a study among 40 cancer patients receiving chemotherapy showed a significant difference in body image between patients with alopecia and patients without alopecia [3]. Furthermore, a study among 29 German women with a gynecological malignancy who lost their hair during chemotherapy found that regrowth of hair after chemotherapy did not necessarily imply recovery of the declined body image [28]. The studies mentioned above all used different methods to measure body image; moreover, these studies did not include patients treated with scalp cooling. Comparisons with the current study are therefore problematic.

In addition, our results showed that, 3 weeks after chemotherapy, successfully cooled patients rated their hair as less important for their body image compared to patients who did experience hair loss. These results may indicate that people only became aware of the importance of hair for their body image once they lost it.

\section{Limitations}

This is an observational study and patient self-selection was therefore inevitable. We do not know how many patients were eligible for scalp cooling and to how many of them it was offered and, finally, how many have accepted that offer. Dropout during the study was most often caused by logistical problems. Furthermore, the sample of scalp-cooled patients was relatively small, which made subanalyses less powerful. In addition, some of the questionnaires used in this study are relatively new and their psychometric characteristics are currently unknown. Nevertheless, the results of this study form an important contribution to the limited information available on scalp cooling to prevent chemotherapy-induced hair loss in cancer patients.
Final remarks

In conclusion, the present study is the first more systematic study that specifically addresses scalp-cooling satisfaction in a multicenter context. This study showed that chemotherapyinduced hair loss is stressful to the majority of breast cancer patients. Hair loss may be prevented by scalp cooling although the success rate in this study was limited. Nevertheless, scalp cooling can be an effective method to prevent hair loss and is tolerated well by patients. However, scalp cooling techniques should be improved because if scalp cooling is unsuccessful, patients' rate their hair loss as more burdensome compared to patients who did not receive scalp cooling.

Acknowledgement We are grateful to all patients for participating in the study. We would like to thank the following hospitals for their friendly cooperation: A. Schweitzer, Dordrecht; Máxima Medisch Centrum, Eindhoven; Elkerliek, Helmond; Mesos Medisch Centrum, Utrecht; St. Elisabeth, Tilburg; Twee Steden Hospital, Tilburg; Gelre, Apeldoorn; Lievensberg, Bergen op Zoom; Amphia, Breda; Catharina, Eindhoven; Sint Anna, Geldrop; Medisch Centrum Rijnmond Zuid, Rotterdam; and Máxima Medisch Centrum, Veldhoven.

Open Access This article is distributed under the terms of the Creative Commons Attribution Noncommercial License which permits any noncommercial use, distribution, and reproduction in any medium, provided the original author(s) and source are credited.

\section{References}

1. Adams L, Lawson $\mathrm{N}$ et al (1992) The prevention of hair loss from chemotherapy by the use of cold-air scalp-cooling. Eur J Cancer Care (Engl) 1(5):16-18. DOI 10.1111/j.1365-2354.1992.tb00140.x

2. Batchelor D (2001) Hair and cancer chemotherapy: consequences and nursing care - a literature study. Eur J Cancer Care (Engl) 10 (3):147-163. DOI 10.1046/j.1365-2354.2001.00272.x

3. Baxley KO, Erdman LK et al (1984) Alopecia: effect on cancer patients' body image. Cancer Nurs 7(6):499-503. DOI 10.1097/ 00002820-198412000-00006

4. Carelle N, Piotto E et al (2002) Changing patient perceptions of the side effects of cancer chemotherapy. Cancer 95(1):155-163. DOI 10.1002/cncr.10630

5. Carver CS, Pozo-Kaderman C et al (1998) Concern about aspects of body image and adjustment to early stage breast cancer. Psychosom Med 60(2):168-174

6. Cash TF, Price VH et al (1993) Psychological effects of androgenetic alopecia on women: comparisons with balding men and with female control subjects. J Am Acad Dermatol 29(4):568-575

7. Coates A, Abraham S et al (1983) On the receiving end-patient perception of the side-effects of cancer chemotherapy. Eur J Cancer Clin Oncol 19(2):203-208. DOI 10.1016/0277-5379(83)90418-2

8. David J, Speechley V (1987) Scalp cooling to prevent alopecia. Nurs Times 83(32):36-37

9. de Boer-Dennert M, de Wit R et al (1997) Patient perceptions of the side-effects of chemotherapy: the influence of 5HT3 antagonists. Br J Cancer 76(8):1055-10561

10. Dean JC, Salmon SE et al (1979) Prevention of doxorubicininduced hair loss with scalp hypothermia. N Engl J Med 301 (26):1427-1429 
11. Dolte KS, Girman CJ et al (2000) Development of a health-related quality of life questionnaire for women with androgenetic alopecia. Clin Exp Dermatol 25(8):637-642. DOI 10.1046/ j.1365-2230.2000.00726.x

12. Dougherty L (1996) Scalp cooling to prevent hair loss in chemotherapy. Prof Nurse 11(8):507-509

13. Edelstyn GA, MacDonald M et al (1977) Doxorubicin-induced hair loss and possible modification by scalp cooling. Lancet 2 (8031):253-254. DOI 10.1016/S0140-6736(77)92877-X

14. Fairlamb DJ (1988) Hair changes following cytotoxic drug induced alopecia. Postgrad Med J 64(757):907

15. Fischer TW, Schmidt $S$ et al (2001) Hairdex: a tool for evaluation of disease-specific quality of life in patients with hair diseases. Hautarzt 52(3):219-227. DOI 10.1007/s001050051293

16. Giaccone G, Di Giulio F et al (1988) Scalp hypothermia in the prevention of doxorubicin-induced hair loss. Cancer Nurs 11 (3): $170-173$

17. Grevelman EG, Breed WP (2005) Prevention of chemotherapyinduced hair loss by scalp cooling. Ann Oncol 16(3):352-358. DOI 10.1093/annonc/mdi088

18. Hopwood P, Fletcher I et al (2001) A body image scale for use with cancer patients. Eur J Cancer 37(2):189-197. DOI 10.1016/ S0959-8049(00)00353-1

19. Janssen-Heijnen MLG, Louwman WJ et al (2005) Results of 50 years cancer registry in the south of the Netherlands: 1955-2004 (in Dutch). Eindhoven Cancer Registry, Eindhoven

20. Katsimbri P, Bamias A et al (2000) Prevention of chemotherapyinduced alopecia using an effective scalp cooling system. Eur J Cancer 36(6):766-771. DOI 10.1016/S0959-8049(00)00012-5

21. Kennedy M, Packard R et al (1983) The effects of using Chemocap on occurrence of chemotherapy-induced alopecia. Oncol Nurs Forum 10(1):19-24

22. Kiebert GM, Hanneke J et al (1990) Effect of peri-operative chemotherapy on the quality of life of patients with early breast cancer. Eur J Cancer 26(10):1038-1042

23. Lemieux J, Maunsell E et al (2007) Chemotherapy-induced alopecia and effects on quality of life among women with breast cancer: a literature review. Psychooncology 17:317-328. DOI 10.1002/pon. 1245

24. Lindley C, McCune JS et al (1999) Perception of chemotherapy side effects cancer versus noncancer patients. Cancer Pract 7 (2):59-65. DOI 10.1046/j.1523-5394.1999.07205.x

25. Macduff C, Mackenzie T et al (2003) The effectiveness of scalp cooling in preventing alopecia for patients receiving epirubicin and docetaxel. Eur J Cancer Care (Engl) 12(2):154-161. DOI 10.1046/j.1365-2354.2003.00382.x

26. Massey CS (2004) A multicentre study to determine the efficacy and patient acceptability of the Paxman Scalp Cooler to prevent hair loss in patients receiving chemotherapy. Eur J Oncol Nurs 8 (2):121-130. DOI 10.1016/j.ejon.2003.10.006

27. Mulders MCMA, Vingerhoets AJJM et al (2008) The impact of cancer and chemotherapy: perceptual similarities and differences between cancer patient, physician and nurse perceptions. Eur J Oncol Nurs DOI 10.1016/j.ejon.2007.10.002

28. Munstedt K, Manthey N et al (1997) Changes in self-concept and body image during alopecia induced cancer chemotherapy. Support Care Cancer 5(2):139-443. DOI 10.1007/BF01 262572

29. Nolte S, Donnelly J et al (2006) A randomized clinical trial of a videotape intervention for women with chemotherapy-induced alopecia: a gynecologic oncology group study. Oncol Nurs Forum 33(2):305-311. DOI 10.1188/06.ONF.305-311

30. Parker R (1987) The effectiveness of scalp hypothermia in preventing cyclophosphamide-induced alopecia. Oncol Nurs Forum 14(6):49-53

31. Pickard-Holley S (1995) The symptom experience of alopecia. Semin Oncol Nurs 11(4):235-238. DOI 10.1016/S0749-2081(05)80003-8

32. Protiere C, Evans K et al (2002) Efficacy and tolerance of a scalp-cooling system for prevention of hair loss and the experience of breast cancer patients treated by adjuvant chemotherapy. Support Care Cancer 10(7):529-537. DOI 10.1007/ s00520-002-0375-y

33. Ridderheim M, Bjurberg $M$ et al (2003) Scalp hypothermia to prevent chemotherapy-induced alopecia is effective and safe: a pilot study of a new digitized scalp-cooling system used in 74 patients. Support Care Cancer 11(6):371-377

34. Ron IG, Kalmus Y et al (1997) Scalp cooling in the prevention of alopecia in patients receiving depilating chemotherapy. Support Care Cancer 5(2):136-138

35. Rosman S (2004) Cancer and stigma: experience of patients with chemotherapy-induced alopecia. Patient Educ Couns 52(3):333339. DOI 10.1016/S0738-3991(03)00040-5

36. Satterwhite B, Zimm S (1984) The use of scalp hypothermia in the prevention of doxorubicin-induced hair loss. Cancer 54(1):34 37. DOI 10.1002/1097-0142(19840701)54:1<34::AIDCNCR2820540109>3.0.CO;2-W

37. Tierney A, Taylor J (1991) Chemotherapy-induced hair loss. Nurs Stand 5(38):29-31

38. Wagner L, Gorely M (1979) Body image and patients experiencing alopecia as a result of cancer chemotherapy. Cancer Nurs 2 (5):365-369. DOI 10.1097/00002820-197910000-00004

39. Williams J, Wood C et al (1999) A narrative study of chemotherapy-induced alopecia. Oncol Nurs Forum 26(9):1463-1468

40. World Health Organisation (1979) Handbook for reporting results of cancer treatment. WHO Offset Publ, Geneva 